Creaney, S (2015) 'Using research to develop inclusive practice in the early years' in Brodie, $\mathrm{K}$ and Savage, K. (eds) inclusive practice in the early years, Routledge: Abingdon.

\title{
10. Using research to develop inclusive practice in the Early Years
}

\section{Sean Creaney}

\section{The aims of this chapter are:}

In this chapter - drawing on the case study and the focus group notes - I shall:

- Explain different approaches to research; namely positivism, interpretivism and action research.

- Provide an overview of the challenges involved in research in the early years, notably the importance of finding ways of capturing the authentic voice of the child in research investigations.

- Outline a range of child friendly methods of inquiry appropriate for researching in the early years.

- Examine some of the issues to be resolved when conducting research with children who have Special Educational Needs (SEN).

- Examine the implications of the children's rights agenda and its relationship to research, most notably the United Nations Convention on the Rights of the Child (UNCRC).

[Start of Case Study box] 


\section{Case Study}

You are an early years professional working in a pre-school. The setting prides itself on its inclusive practice and is committed to promoting the views and rights of children. The team works hard to recognise and value different languages used by practitioners, children and families and makes good use of published policies that acknowledge a range of family structures.

However, you are concerned that the level of support given to children who have Special Educational Needs (SEN) fails to enable them to access the full range of play and learning opportunities. You are not sure how to gather the views, opinions, perspectives and experiences of children, within the setting, who have SEN. You are aware of participatory action research as a possible approach; however, you are unsure of the practicalities and ethics, particularly with regard to the possibility of these young children expressing their needs and experiences unambiguously.

\section{Initial Questions:}

1. How do you know what the needs of the child are?

2. Does this knowledge incorporate the child's point of view?

3. How can you know what the child feels or wants? What makes her happy or causes her anxiety?

4. How do you ensure that the child is listened to and what they say is acted upon?

5. As a researcher what forms of data collection are available to you for capturing the perspectives and experiences of the child?

6. How can you be sure that your interpretation of the evidence is consistent with the needs of the child and the family - rather than convenient for the early years team? 


\section{Further questions}

1. What concerns would you want to identify and address to make sure that your research is ethical? How would you monitor the research process to ensure an ethical approach?

2. Your research starts from an assumption - an aspect of team practice can be improved on. How can you be sure that this assumption does not lead and shape your research?

3. How can your findings be shared with children and their families?

4. Addressing one aspect of practice that could be improved might lead to subsequent neglect - or lower priority being given - of other areas. How can the team guard against this?

This is a lot of questions! You may not feel able to answer them all right now - but discuss some of them with those that you work with and make some notes about how you might begin to answer these questions. If you have any initial thoughts about how you would tackle this issue as a reflective practitioner note those too. At the end of the chapter return to your first thoughts and add to them.

[End of Case Study box]

\section{Types of social research}

Early years practice is necessarily creative and innovative. An enquiring, investigative culture should be encouraged (Ingleby and Oliver, 2008). This increases the likelihood that 
practitioners are clearer about 'what works' and 'what does not' with children and families (Ingleby and Oliver, 2008).

Practitioners have an intuitive understanding of this. I met with a group of experienced early years practitioners and Stacey, one of the focus group participants, said, 'we need to understand what works and why - research can help us in that'.

Research is important. It helps to develop inclusive practice. It has real benefits for children and young people. As Hayley, another focus group member said, research is 'not something we do only when we have the time for it - we do it all the time to improve our practice'.

Two of the most significant theoretical perspectives on research will be outlined before investigating the types of research methods appropriate for generating data on what does and does not work. In addition, a third approach, namely action research, is discussed, as it has become influential amongst Early Years practitioners.

Two broad approaches to research are commonly identified and, unhelpfully, are often presented as alternatives in that as a researcher it is suggested that you must adopt one stance or the other. In reality most care and education research combines some elements of both.

Positivist approaches (or positivism in general) derive from the methods developed by natural scientists over hundreds of years and are represented as objective, scientific and free from bias. Following this approach any data collected should be carefully controlled (to measure the significance of identified variables) to allow for the testing of theories and hypotheses and to enhance the capacity to make reliable predictions (McKechnie, 2002: 48). Some social scientists - including those working in early years care and education - have 
borrowed from the practice of chemists, physicists, and other natural scientists. Positivist social scientists seek - often through the collection of observed and measured statistical data - to test ideas and concepts and to produce findings that can be generalised (Denzin and Lincoln, 1994). For example 'if we want to know how many children have experienced the death of a parent we must collect appropriate statistics' (Green and Hogan, 2005:5). Or if we want to know how much time boys spend in the book corner (compared with at the sandpit) we would observe and record our findings. As Green and Hogan (2005) acknowledge though, statistics do not 'account for the rich variety of experience within the early years context' (Ingleby and Oliver, 2008:103). It is for that reason that some researchers in education, and other social sciences, start from another perspective.

An interpretative theoretical perspective differs somewhat in its outlook to positivist research; rather than starting from a hypothesis to be tested, interpretative approaches allow the 'theory to emerge from the data once it has been gathered, and may be constantly adjusted as more data emerges' (McKechnie, 2002: 48). It is an approach that focuses on experiences, viewpoints and perspectives of the 'social world' (Ingleby and Oliver, 2008). Indeed, it is argued that 'The creativity of children and Early Years practitioners may be captured [best] by placing an emphasis on researching the process of interaction' (Ingleby and Oliver, 2008: 103). Critics of this approach to research argue that since two different researchers can offer two different interpretations what value can we attach to any reported 'findings'?

It has been argued that interpretative, qualitative research approaches are more appropriate to early childhood research than positivist, quantitative based investigations (Lewis and Lindsay, 2000). There is, however, a third approach to research that differs to 
positivism and interpretivism and which has become influential. Action Research is committed to the idea of 'improving practice'. Rather than gathering data and generalising the research findings (which is central to the positivist approach), action researchers start from the presumption that what they are looking at is 'particular' and 'specific'. Reflective practice is at the heart of action research: problems are identified, data is gathered and analysed, and then different ways of working are described and implemented. This process is then repeated where the 'new' approach is evaluated in a cyclical process.

This approach to Early Years research may be important for a number of reasons. If a planned intervention or strategy is not working as intended or as expected the reasons for this can be explored, and identifying and implementing alternative strategies improvements can be made. In addition to this, promising approaches can be highlighted, shared and used to inform practice. Optimists might argue that this research may have an impact on government policy and guidance.

If Early Years practitioners are to be aware of new initiatives, and the potential they offer in practice, they need to engage in reflective research. This point was raised and discussed by the focus group.

Sarah explained how only by action research could she explore solutions to challenges in the work place. The challenge Sarah referred to was behaviour management. More specifically Jess suggested that it would be valuable to 'look at how children are included holistically to see if they are struggling and to see if additional support or a planned intervention is appropriate'. 
Of course Early Years practitioners do not work in a political or economic vacuum and it is not sufficient to 'wish' for something to happen. Claire reminded the group of the frustrations and cautioned that 'sometimes though we have to wait for the money before we implement any support strategies'. There are further challenges too in the workplace. For example, Molly reflected upon her experiences attempting to conduct research with children who have speech and language delay. Despite her extensive professional experience Molly still finds that there are instances when she has difficulty understanding what children are saying. Molly drew on her undergraduate studies to develop a research strategy that might produce the most helpful data. Recognising that for young children especially being 'tested' can be stressful - and that might further limit communication skills - she opted to use non-participant observations as a research method.

The action research approach has, at the heart, a desire to transform practice for the better, 'providing the space for participants to review activities and achievements and to carry out ongoing tasks of evaluation and revision' in order to inform future practice (Smith, 2009: 128). This may be especially significant as we seek to develop and improve an inclusive practice that recognises the needs and contributions of individuals. More specifically, ideally the child identifies their own needs, and is given power and control over the research process by having responsibility for devising the research questions, through to analysing the findings and the implementation of new forms of practice intervention. I will return to participatory approaches later on in this chapter. However, before that, I want to explore the ideas behind involving young children in research.

\section{Involving young children in research}

[Start of Research Results box] 
We sometimes underestimate children (... ) we shouldn't be afraid to ask them what they think.

(Jess)

Your researching should be natural, whilst the children are in play

(Sarah)

[End of Research Results box]

Early Years practitioners are more aware than most that young children are innately capable of 'processing' and 'understanding' information, yet this capacity is frequently underestimated by researchers who presume that young children 'cannot understand' (Gray, 2012:69).

Over the last 20 years or so an approach that recognises and values the capacity of young children to give voice to their feelings and experiences has gained momentum. This is reflected in some measure in statements such as the United Nations Convention on the Rights of the Child (UNCRC) and this has helped challenge the presumption that children are objects to be studied and have findings applied to (Kirby, et al., 2003).

Indeed, one of the focus group participants Rosie stressed the importance involving children in research. During discussions Rosie referred to the importance of adhering to the UNCRC and more specifically honouring 'freedom of speech'. Rosie went on to argue that 'you shouldn't not involve children; you should always ask for their opinion'. However, in relation to the case study, how much involvement and say can children have over the research 
process? A further question relevant here: if is it important to 'act upon' what a child has said, how can we know what young children with communication difficulties tell us? In relation to children's rights, although the UNCRC purports to be a 'legally binding international instrument', in the UK it has no legal basis: the principles set out are more 'aspirational' than 'enforceable' (Greig, et al., 2013: 204). Nevertheless, one of the four core principles outlined within the UNCRC is respect for the view of the child. Article 12 is most relevant for research purposes as it promotes the active involvement of children in matters that affect them and deems the child to be the key decision maker:

'state parties shall assure to the child who is capable of forming his or her own views the right to express those views freely in all matters affecting the child' (UN, 1989).

Furthermore, in relation to participation in research, Article 12 states that 'children have the right to be consulted and taken account of' (Morrow and Richards 1996, cited in RobertsHolmes, 2005: 54). In addition to the UNCRC, the Children Acts of 1989 and 2004 advocate the involvement of children in the research process, especially when it concerns their welfare. However, too often adults - sometimes researchers, sometimes politicians and policymakers - are too ready to decide that a child is not 'capable of forming his or her own views' and as a result the 'views, opinions, feelings and wishes, are neither sought nor acted on. Children are effectively silenced and ultimately oppressed by the adults who are in charge of them' (Greig, et al., 2013:205).

There are some more hopeful and encouraging signs. In recent years there has been a shift in thinking regarding the involvement of children in research. Rather than being viewed as the 'developmental child' or 'child that needs protecting', children are now deemed to be 
socially active decision makers (Hendrick, 1997), regarded as 'knowers' (Palaiologou, 2012:1) and invited to partake in research 'on the basis of who they are, rather than who they will become' (Moss and Petrie, 2002:6).

Prior to this relatively new way of thinking, it was adults who decided what was best for the child (James and Prout, 1990). The child was considered to be a human becoming rather than a human being (Quortrup, 1987) as they were deemed to be unable to express an informed opinion due to their age and perceived social incompetence.

In this model of childhood first and foremost it is the failings of the child that are identified, starting from the belief that children do not have anything of value to add to the research process (David, 1992). However, the need to listen to the child and deem them to be 'experts in their own lives' (Langsted, 1994) has developed as a perspective out of a critique of the child as a passive non-participant model. This is evident with the emergence of 'the new sociology of childhood' (James and Prout, 1997) and subsequent promotion of participatory research methods.

This 'new sociology' emphasises the practice of reflection. Here practitioners are expected to reflect not only on the choice of methodology but also the research methods chosen and interpretation of the findings (James, 1999). Importantly this sociological paradigm prompts researchers to be mindful of the appropriateness of the research techniques used to gather data. Indeed, it is argued that to prevent a lack of participation and engagement in the research process (and arguably to help ensure that children enjoy partaking in the study) 'researchers need to employ methods that tap into the different skills, or competencies, that children have, for example, drawing, stories and written work' (McKechnie, 2002: 45). 
Furthermore, from an epistemological perspective (that is the theory of knowledge), by 'attending to what children say, we gain access to the meaning they themselves attach to their experiences' (McKechnie, 2002: 45). These methods are used with children in their 'natural settings', to uncover authentic knowledge, with a view to 'making sense' of the thoughts expressed by the research participants (Denzin and Lincoln, 1994:2).

In other words, these qualitative approaches strive to help the researcher reveal and report the attitudes or actions of individuals from the subjective perspective of the participant involved in the study (Bryman, 1988). Description and context is important in qualitative research and in relation to the child's voice, these approaches allow for the child to 'have a say' and 'be heard' (Grieg and Taylor, 1999:46).

For some the notion that research is 'subjective' is counter-intuitive. Surely the whole point of research, some will say, is to 'find out, to establish what is true and what is false'? If that is the case researchers should strive to be objective. In the fields of education and social science most qualitative researchers doubt that there is an objective reality. Rather, 'multiple realities' exists within society. What is 'good' and 'successful' for some may be interpreted as 'damaging' by others. It really is very difficult, if not impossible, to have objective measures of achievement when it comes to care and education.

It is the role of the researcher to study these socially constructed realities by exploring the experiences, viewpoints and perspectives of the research participants (Cresswell, 1998). Subjectivity is prioritised within this approach and deemed to be highly important. However, it must be acknowledged here that early years practitioners face many challenges initiating activities 'with children' and giving them a voice: 
[Practitioners] who are asked on the one hand to adhere to an ideological shift of actions 'with children' while on the other they are required by officialdom to measure children against models and a set of standards laid down in regulations. (Palaiologou, 2012:4)

As Palaiologou (2012:4) notes, a 'mismatch' exists, where the emphasis is on giving voice and adhering to the wishes and needs of the child alongside practice that is 'laid down' by 'officialdom' and deemed to be in the child's best interest:

The dilemma here is that practitioners try to act according to reason and hence attain ethical practice, yet external practices are imposed upon them in the name of the good of the children.

In other words, although practitioners are required to involve children in activities, and promote shared decision making, the 'audit society' (Power, 1997) has crept into Early Years where practitioners have to comply with the statutory framework (Williamson, 2012:180). This has resulted in developmental progress being measured against prescribed standards of learning, development and welfare - as set out in the Early Years Foundation Stage (EYFS). In our focus group discussion Leah emphasised that the EYFS acknowledges that 'every child is different', though Sarah questioned how 'fair' and 'inclusive' the EYFS actually is, as it requires that children are 'doing this at this stage and this age'. (Jo Basford's chapter in this book on Assessment is relevant here).

The EYFS has many strengths, not least the enhancement of the child's welfare (safeguarding and child protection issues are given priority in the framework). However, although the intentions of the framework are benevolent, arguably it can be 
counterproductive as it may constrain a practitioner when it comes to giving the child a voice.

\section{Ethical and inclusive research practice with children who have Special}

\section{Educational Needs}

Even children with severe learning disabilities or very limited expressive language can communicate preference, if people who understand their needs and have the relevant skills to listen ask them in the right way. (Department of Health, 1991:14, cited in, Ellis and Beauchamp, 2012:48)

Early Years practitioners will need to draw on all their skills and experience if they are to involve young children in research. Children may be unwilling or unable to engage directly with the research process and if researchers infer messages from observed behaviour that message ceases to be the child's voice. This whole process may be more complex when working with children who have Special Educational Needs (SEN) (Ellis and Beauchamp, 2012). This may result from the limited experience that practitioners have when it comes to specific additional needs when much learning takes place 'on the job'. Before discussing these challenges and identifying ways to address them, it is important to define key terms that form the next part of this chapter.

Although the concept of SEN is contested, put simply, a child with a SEN is defined to be a person who has a difficulty or disability that impacts on their ability to learn - that is specific, moderate, severe, profound or multiple - and demonstrates a need for special educational provision (DfES, 2001). Children who have SENs (for example behavioural or social difficulties, dyslexia, or attention deficit hyperactivity disorder) may, because of ill- 
considered or designed provision, experience problems in accessing learning opportunities (DfES, 2001).

Insufficient professional training, poor communication with the family, or inadequate support from other professional services may all contribute to the failure of effectively communicating with children. There is a heightened risk that assumptions will be made about what is 'said' and how it is understood, recorded and reported (Ellis and Beauchamp, 2012).

However, with regard to engagement and participation, the Children Act 1989 along with formal ratification of the UNCRC provided a platform for the child's voice to be heard and in turn for child-centred practice to flourish through a focus on allowing children individually to be respected 'in their own right' (Green, 2012).

Article 12 of the Convention provides that the views of children are to be taken seriously through 'active participation'. The competence of a child to express those views is determined in accordance with 'the age and maturity of the child' (DOH, 1999:46). This notion of 'competence' is likely to be problematic; it might well be that young children under the age of five, for example, may be prevented from taking part and having their voices heard because they are presumed to be 'incompetent'.

Article 13 , on the other hand, differs somewhat in its focus 'valuing a child's participation in any shape or form relative to the individual' (Green, 2012:21). This Article also demonstrates a 'commitment to conducting research with children, rather than on [them]' (O'Kane, 2008:125). In order to ensure that this commitment is realised, researchers should not employ research methods that are designed for adults. Rather, careful consideration 
should be given to the appropriateness of the techniques for use with children. In particular ethical considerations are important here and the methods chosen need to be fit for purpose - capable of capturing children's experiences and understandings of the social world effectively (Thomas and O'Kane, 1998).

However, there are further ethical considerations that need to be made when researching with younger children with SEN. Although there are various codes of practice in existence that offer guidance (See British Educational Research Association (BERA, 2004) and the British Psychological Society (BPS) for example) on the process of gaining informed consent, and adhering to matters of confidentiality and anonymity, the challenges involving young children with SEN in research remain.

Some children, with diagnosed and defined SEN, may have cognitive and emotional difficulties and may be unable to understand the elements that make up the research process. In such circumstances researchers should remain committed to the task of building a relationship by 'getting to know' the child and understanding their needs and wants, demonstrating a firm desire to include the child fully (Hart, 1992) in the research process. There are difficult balances to be struck when it comes to carrying out research that is believed to be in the best interests of the child's care and education, yet when there is no certainty that the child understands what is happening or what they are a part of.

If that is the case - and clearly with very young children that must be true - then it is imperative that the parents or carers are fully involved and consent to the proposed research. It is also important to establish a good working relationship with parents or carers, as they may be able to offer valuable insight into the child's wants and needs and in turn 
may be able to help the child understand the research process, and in particular what is to be expected of them as a participant:

'parents hold key information and have a critical role to play in their children's education. They have unique strengths, knowledge and experience to contribute to the shared view of a child's needs and the best ways of supporting them' (DfES, 2001:16).

This is another possibility, however, as Hayley explained in the focus group discussion; 'sometimes parents and carers can make inclusive practice difficult'. Rosie amplified when suggesting that undoubtedly the intentions of the parent or carer may be benevolent - and what they perceive to be 'in the best interest of the child' - they may prevent their child from expressing their own opinion or may 'withdraw their child' from the study. The parent or carer may not want the child to be seen in a 'negative light' or they may deem the child to be incapable of answering the question/s asked. In some instances parents do not accept that their child may have additional needs or may resist what they see as the stigma of being identified as having SEN. However, as the researcher, you may believe the child is capable of understanding the question and you may wish to explore this possibility with the parent or carer.

[Start of reflective practices box]

\section{Reflection point}

1. Think of a child that you have worked closely with who has clearly defined additional needs. How do you know what she thinks and feels about her care and education? 
2. What information do you share with her parents (remember this is a two-way process, each of you 'gives' and 'receives')?

3. You want to review the effectiveness of your planning when it comes to meeting the child's needs - how would you involve the child and the parents in that review?

[End of reflective practices box]

It is good practice to invite relevant professionals and family members to take part in the research, at the earliest opportunity, to help with designing appropriate child friendly methods of engagement. It is important to develop a trusting relationship early on. Some researchers are nervous that by getting too close to the child and the family - and developing an emotional attachment - it becomes even harder to be objective or balanced. It follows, from this view, that the validity of any findings may be challenged. However, developing a relationship with the participant/s will be vital in deciding how to communicate effectively with the child.

There will be a number of specific and practical matters to be resolved in any event. For example, it is important to decide when and where the research will take place. All parties must agree the venue, including, if at all possible, the child. Any change in routines or established patterns can be disturbing and affect the child's 'normal' behaviour or responses.

When it comes to finding ways of capturing the 'voice' of the child, when the spoken word is not an option, it may be that photographs or scrupulously observed body language are valid. Though there is always a risk that adults will place their interpretation, their language, and their values on what they see a child do. 
There are additional matters to consider, such as the unequal power relationships that may exist between adults and children. It should not be presumed, though, that adults always hold power over children. Even very young children learn how they might manipulate adults. Researchers have a responsibility to look at where power is held and is exerted and must take care to empower the child participant. This mirrors the idea discussed earlier that children should be treated as 'subjects', invited, or rather actively encouraged to take 'ownership' rather than 'objects' where research is done 'to' children. This is at the heart of participatory approaches in research.

With regard to ethics, information regarding the purpose/s of the study needs to be properly communicated with the child or her parent. Only then is it possible to make an informed decision regarding whether to participate or not. Consequently, alternative forms of communication may be necessary; these include sign language and/or Braille. In addition to these techniques, some researchers may ask the child to produce a handprint in paint to demonstrate approval of participation. However, questions may be asked regarding whether the child understands the process, including the implications of taking part in the study.

There are further ethical issues to consider. For example, children may not wish to inform the researcher that they do not want to answer a certain question or even withdraw from the study (Ellis and Beauchamp, 2012). One way of overcoming these difficulties would be to introduce a 'traffic light' activity. Although this activity would need to be designed as appropriate to the child's age and ability, here children 'hold up' yellow cards (if they wish to not answer a question) or a red cards (if they wish to withdraw from the session or study 
completely) (Knight, et al., 2006). This activity would need to be practised beforehand in order to ensure that the participants fully understand the mechanics of it.

\section{Participatory approaches}

It has been argued that there is a lack of convincing evidence that being involved in research, even in a 'truly participatory' sense, has any actual benefits for the children participating (Hill, et al., 2004). Despite this, there are a number of potential benefits (Jones and Welch, 2010) including increasing the effectiveness of the service, the enhancement of the child's political voice, and the opportunity for the vulnerable child to 'speak out' against forms of oppression and be listened to.

For participatory approaches to capture of the voice of the child 'effectively' there are certain standards that should be upheld, namely adherence to a value base consisting of trust and respect; and appropriate training and supportive mechanisms for participations on how actually to contribute in a meaningful way (Lansdown, 2001).

As Tilly, one of the focus group members, said, 'we have to rely a lot on observations for our data'. When using observations though, as a research tool, they should be interactive, and child-centred. Indeed, as part of a participatory approach to research the child should be given power and control, to a certain extent, over the research agenda and given a say regarding the activities deemed most suitable. The Mosaic approach to research is a good example of this.

It is multi-method, comprising a range of 'tools' - verbal and visual (Greig, et al., 2013), designed to elicit the perspective of the child participants in creative ways to adhere to differential levels of engagement. The Mosaic approach plays to a child's strengths rather 
than 'deficits' (Clark, 2004:144) utilising fun, engaging methods, to help children express their views comfortably.

Although the Mosaic way of researching can be successful when contributing to service evaluations for example, it is an approach that may not be completely free from adult control over the research agenda. Concerns may still be raised over a child's privacy, and whether an accepted culture of 'listening' actually occurs in practice (Clark and Moss, 2001). Furthermore, although the participatory skills of the participants can be enhanced by the use of various tools (namely maps and photos for example) these methods are not without practical challenges.

Other methods may be advocated, namely drawing workshops and diaries. Some children may enjoy partaking in these exercises but others may have had negative experiences and be nervous or reluctant to take part. This is just another example of the importance of knowing the child and being sensitive to her feelings and responses. Having said that, if the method of a diary is well designed prior to its use for research purposes (Punch, 2002), it may provide a fascinating insight what it is like to be a child.

Rather than an adult deciding the most suitable methods to be used, in accordance with the children's rights movement, researchers should empower children to have a say on suitable methods. Traditional research techniques, such as focus groups, and individual interviews (although they will need to be age appropriate and be consistent with the development of the child) can prove a useful consultative platform for encouraging child participation. With regard to children who have severe and complex difficulties learning, and more specifically those less than, say, five years of age, written exercises may not be suitable. In turn, roleplay exercises may provide a better basis for the children to express themselves. 
Another example of a how to make the research process child-centred to find ways of allowing children to select or provide images - be they drawings or photographs - rather than asking children to comment on images provided by the researcher.

Related to the above techniques is the ethnographic approach. Proponents argue that it is the most appropriate way of grasping the perspective from 'the point of view' of those being studied (Denscombe, 2007). In this approach the method of (participant and/or nonparticipant) observation is often used. However, there are clearly difficulties note-taking when observing children directly. A further implication of this approach (linked to action research - noted at the beginning of this chapter) is that, as a researcher, you may experience difficulties remaining 'impartial' (Chambers, 1983) as a result of the intimate relationship you may have formed with the participants.

You may choose to observe at a distance, in order to remain more objective and increase the validity of the findings. Though in Early Years settings children may be more comfortable and more familiar with adults sharing their play and learning at close quarters. Having a note-taker sitting in the corner may be more disturbing for a child and she or he may question why you are there.

There will be other issues that experienced researchers are familiar with in their work with children (though adult participants may respond similarly!). In the focus group Gemma reminded us that researchers should be aware that a child may say what they think the researcher wants them to say and, in turn, may be unwilling to express their opinions openly. As Leah said 'children may act differently if there is someone new in the room'. Furthermore, there are ethical, power-related issues to consider, as Leah also pointed out: 'children might feel they are doing something wrong if you're watching them'. 
There are other factors that experienced researchers will be aware of. For example, the child may feel compelled to answer in a certain way due to their parent or carer being present during the research study. However, one way potentially to overcome this issue is to encourage the child to discuss the thoughts and feelings of others rather than their own.

In our focus group discussions Stacey said that with regard to research findings ultimately '(...) it is our interpretation. It is not what the children are saying'. An awareness of this is critical if as researchers we are to review our findings and report and share them as honestly as we can, taking care to be clear about what we are inferring from the evidence we have collected. Interpretation must be ours - but we should explain our evidence as clearly as possible to leave open the prospect of other interpretations.

\section{Conclusions}

Researchers adopting a quantitative position focus on 'the measurement and analysis of causal relationships' rather than the process of social experience (Denzin and Lincoln, 2005: 10). On the other hand, qualitative researchers 'seek answers to questions that stress the socially constructed nature of reality, the intimate relationship between the researcher and what is studied' (Denzin and Lincoln, 2005: 10).

Early childhood studies researchers use research studies that are interpretative and qualitative widely. However, because of the subjectivity or 'intimate relationship' building, it becomes difficult for a researcher, operating from within this paradigm, to demonstrate the validity, reliability and repeatability of research findings: 'would two different researchers interpret a participant's voice in the same way?' (McKechnie, 2002:10). To counteract these criticisms, qualitative researchers note the importance being reflective throughout the process. They argue that these reflections should be documented, in the form of a research 
diary, to add credibility to the findings of the study. Indeed, the focus group participants noted the importance reflecting on practice. To quote the words of one participant, Leah: 'you need to reflect on what worked and what didn't'.

It would be rather naïve to suppose that the process of research is 'neat' and 'uncomplicated'. Trying to collect the experiences and views of young children with varied communication skills, different degrees of self-confidence and trust; trying to engage parents and carers in the research process make for complexities that can only represented by approximation. This is not - and should not be represented as - an exact science.

[Start of reflective practice box]

\section{Final Reflection Point}

Please go back to the notes that you made in response to the initial questions in this chapter. Having worked through this material, review and revise your first notes and draw up an action plan for the next piece of action research you plan to carry out in your setting. In particular identify how you will include the child's authentic voice and show where your own interpretation will be evident.

[End of reflective practice box]

\section{References}

BERA (2004) Revised Ethical Guidelines for Educational Research, Available from: http://www.bera.ac.uk/publications/pdfs/ETHICA1.PDF

Bryman, A. (1988) Quantity and Quality in Social Research. London: Unwin Hyman

Chambers, R. (1983) Rural Development: Putting the Last First. Longman, London. 
Clark, A. (2004). The mosaic approach and research with young children. In V. Lewis, M. Kellett, C. Robinson, S. Fraser \& S. Ding (Eds.), The reality of research with children and young people London: Sage.

Clark, A., \& Moss, P. (2001). Listening to young children: The mosaic approach. London: National Children's Bureau and Joseph Rowntree Foundation.

Cresswell, J. W. (1998). Qualitative inquiry and research design: Choosing among five traditions. Thousand Oaks, CA: Sage Publications.

David, T. (1992) 'Do we have to do this?' The Children Act 1989 and Obtaining Children's Views in Early Childhood Settings Children and Society Vol. 6 No. 3 pp. 204-211

Denscombe, M. (2007) The Good Research Guide for Small-scale Social Research Projects (3rd ed) Maidenhead: Open University Press.

Denzin, N.K., and Lincoln, Y.S. (2005). Introduction: The discipline and practice of qualitative research. In N.K. Denzin \& Y.S. Lincoln (Eds.), The Sage Handbook of qualitative research (2nd ed.). Thousand Oaks, CA: Sage.

Denzin, N. K. and Y. S. Lincoln, Eds. (1994) Handbook of Qualitative Research London: Sage Department of Health DoH (1999) Convention on the rights of the child, second report to the UN committee on the rights of the child by the United Kingdom. Executive summary. London: TSO.

DfES (2001) The special educational needs code of practice. London. HMSO.

Ellis, C., \& Beauchamp, G. (2012). Ethics in researching children with special educational needs. In Palaiologou, I. (Ed.), Ethical practice in early childhood. London: Sage. 
Gray, C. (2012). Ethical research with children and vulnerable groups pp. 64-83 In Palaiologou, I (Ed.), Ethical practice in early childhood. London: Sage.

Green, D. (2012). Involving young children in research. In Palaiologou, I. (Ed.) Ethical practice in early childhood. London: Sage.

Green, S. and Hogan, D. (2005). Researching Children's Experiences: Approaches and Methods. London: Sage

Greig, A. and Taylor, J. (1999) Doing Research with Children. London: Sage.

Greig, A., Taylor, J. and MacKay, T. (2013)(3 ${ }^{\text {rd }}$ Ed) Doing Research with Children. London: Sage.

Hart, R. (1992) Children's participation: From tokenism to citizenship Florence: UNICEF International Child Development Centre.

Hendrick, H. (1997). Constructions and reconstructions of British childhood: An interpretative survey, 1800 to the present. In A. James and A Prout (Ed.) Constructing and Reconstructing Childhood London: Falmer Press.

Hill, M., Davis, J., Prout, A. and Tisdall, J. (2004). Moving the Participation Agenda Forward. Children and Society Vol. 18, No. 2, pp. 77-96.

Ingleby, E., and Oliver, G. (2008). Applied Social Science for Early Years Exeter: Learning Matters.

Jones, P. and Welch, S. (2010) Rethinking children's rights: attitudes in Contemporary Society. New York: Continuum International Publishing group. 
James, A., \& Prout, A. (Eds.). (1990). Constructing and reconstructing childhood. London: Falmer.

James, A., \& Prout, A. (Eds.). (1997) Constructing and reconstructing childhood. London: Falmer.

James, A. (1999) 'Researching children's social competence: methods and models', in M. Woodhead, D. Faulkner \& K. Littleton (eds.) Making Sense of Social Development, London: Routledge

Kirby, P., Lanyon, C., Cronin, K. and Sinclair, R. (2003) Building a culture of participation London: Department for Education and Skills.

Knight, A., Clark, A., Petrie, P., and Statham, J. (2006) The views of children and young people with learning disabilities about the support they receive from Social Services: A review of consultations and methods, Report to DCSF, London: Thomas Coram Research Unit. Langsted, O. (1994) Looking at Quality from the Child's Perspective in P. Moss \& A. Pence (Eds.) Valuing Quality in Early Childhood Services: New Approaches to Defining Quality. London: Paul Chapman Publishing.

Lansdown, G. (2001). Promoting children's participation in democratic decision-making London: UNICEF

Lewis, A. and Lindsay, G. (eds) (2000) Researching Children's Perspectives Buckingham: Open University Press.

McKechnie, J. (2002) 'Children's Voices and Researching Childhood', in B. Goldson, M. Lavalette and J. McKechnie (eds) Children, Welfare and the State. London: Sage. 
Moss, P. and Petrie, P. (2002) From Children's Services to Children's Spaces: Public Policy,

Children and Childhood. London: Routledge Falmer.

O’Kane, C. (2008) 'The development of participatory techniques', in Christensen, P. \& James, A., (eds), Research with Children: Perspectives and Practices, 2nd edn, London: Routledge, pp $125-155$.

Palaiologou, I., (Ed) (2012) Ethical Practice in Early Childhood London: Sage

Power, M. (1997) From risk society to audit society. Soziale systeme Vol. 3 No. 1 pp. 3-2

Punch, S. (2002) 'Research with Children: The Same or Different from Research with Adults?'

Childhood, Vol. 9 No. 3 pp. 321-341

Quortrup, J. (1987) Introduction: the sociology of children International journal of sociology, Vol. 17 No. 3 pp. 3-37.

Roberts-Holmes, G. (2005) Doing your Early Years research project: a step by step guide. London: Sage.

Smith, R. (2009) Doing Social Work Research. Maidenhead: McGraw Hill.

Thomas, N. and O'Kane, C. (1998) 'The Ethics of Participatory Research with Children' Children and Society Vol. 12 pp. 336-348.

United Nations (UN) (1989) Convention on Rights of the Child, New York: United Nations.

Williamson, J. (2012). Ethics when inspecting early years practice. In Palaiologou, I. (Ed.), Ethical practice in early childhood. London: Sage 